\title{
Biodegradable pins for lateral condylar fracture of the humerus with an early delayed presentation in children: a retrospective study of biodegradable pin vs. Kirschner wire
}

\author{
Jin Li' ${ }^{1}$, Saroj Rai ${ }^{2}$, Yun Gao ${ }^{3}$, Renhao Ze ${ }^{1}$, Xin Tang ${ }^{1}$, Ruikang Liư ${ }^{4}$ and Pan Hong ${ }^{1 *}$ [D
}

\begin{abstract}
Background: The clinical outcome of open reduction and internal fixation (ORIF) for delayed lateral condylar fracture of the humerus (LCFH) varies in different studies, but ORIF for LCFH with an early-delayed presentation usually resulted in significant improvement of elbow function. Early delayed presentation is defined as a period of 3 to 12 weeks from the injury. This study aims to compare the clinical outcomes of biodegradable pin (BP) vs. Kirschner wire (KW) in the treatment of LCFH with an early delayed presentation.

Methods: LCFH with an early-delayed presentation treated with KW or BP were retrospectively reviewed in our hospital. The patients were divided into two groups KW $(n=17)$ and BP group $(n=26)$. Baseline information, including sex, age, operative side, duration from injury to surgery, and implant choice, was reviewed. Radiographs and medical records were collected from the Hospital Database.

Results: In all, 17 patients (male/female, 9/8) in KW and 26 patients (male/female,13/13) in the BP group were included. The age showed no statistically significant difference between the KW $(52.3 \pm 10.2$, month) and the BP (56.1 \pm 10.7 , month), $(P=0.258)$. At the last follow-up, there existed no statistically significant difference between the two groups concerning Baumann's angle $(P=0.272)$ and carrying angle $(P=0.911)$. The MEPS at the last follow-up was better in the KW group $(91.1 \pm 2.7)$ than the BP group $(89.2 \pm 3.0),(P=0.048)$. There was no case of nonunion or malunion in both groups. The incidence of fishtail deformity was $(8 / 17,47.1 \%)$ in $\mathrm{KW}$ and $(13 / 26,50 \%)$ in the BP group. The incidence of lateral prominence was $(5 / 17,29.4 \%)$ in the KW and $(7 / 26,26.9 \%)$ in the BP group. Furthermore, the incidence of implant prominence was higher in $\mathrm{KW}(12 / 17,70.6 \%)$ than $\mathrm{BP}(0)(P<0.001)$.

Conclusion: Open reduction and internal fixation for LCFH with an early-delayed presentation produced satisfactory outcomes. Biodegradable pin is a good alternative to Kirschner wire, with comparable clinical outcomes.
\end{abstract}

Keywords: Delay, Lateral condylar fracture, Children, Biodegradable pin

* Correspondence: hongpan2013@foxmail.com

'Department of Orthopaedic Surgery, Union Hospital, Tongji Medical College, Huazhong University of Science and Technology, Wuhan 430022, China

Full list of author information is available at the end of the article

C The Author(s). 2020 Open Access This article is licensed under a Creative Commons Attribution 4.0 International License, which permits use, sharing, adaptation, distribution and reproduction in any medium or format, as long as you give appropriate credit to the original author(s) and the source, provide a link to the Creative Commons licence, and indicate if changes were made. The images or other third party material in this article are included in the article's Creative Commons licence, unless indicated otherwise in a credit line to the material. If material is not included in the article's Creative Commons licence and your intended use is not permitted by statutory regulation or exceeds the permitted use, you will need to obtain permission directly from the copyright holder. To view a copy of this licence, visit http://creativecommons.org/licenses/by/4.0/. The Creative Commons Public Domain Dedication waiver (http://creativecommons.org/publicdomain/zero/1.0/) applies to the data made available in this article, unless otherwise stated in a credit line to the data. 


\section{Background}

Lateral condylar fracture of the humerus (LCFH) is a common elbow injury in children [1]. Early diagnosis with appropriate treatment normally yields satisfactory outcomes [2]. However, if the diagnosis is delayed or the reduction is lost after initial conservative treatment, malunion or nonunion usually occurs. Patients suffering from malunion or nonunion usually present with persistent pain, decreased range of movement (ROM) of the elbow joint, cubitus valgus deformity, and delayed ulnar nerve palsy [3-5]. The current treatment method for neglected or delayed LCFH is controversial, which ranges from observation with periodical follow-up to open reduction and internal fixation (ORIF) $[3,4,6]$. The clinical outcomes following ORIF of the LCHF have been reported differently in different studies [3-5, 7], however, ORIF for an early-delayed presentation usually resulted in significant improvement of elbow function [3].

Utilization of Kirschner wire (KW) for the fixation of LCHF with an early-delayed presentation is a costeffective choice $[3,8,9]$, so it is our preferred choice before the introduction of biodegradable pin (BP). Earlydelayed presentation is defined as a period between 3 to 12 weeks from injury. This study aims to compare the clinical outcomes of BP with KW in the treatment of LCFH with an early-delayed presentation.

\section{Methods}

LCFH with an early-delayed presentation treated with KW or BP from January 2010 to January 2016, at Wuhan union hospital, Tongji Medical College, Huazhong University of Science and Technology were retrospectively reviewed. This study was approved by the Ethics Committee of Tongji Medical College, Huazhong University of Science and Technology (IORG No: IORG0003571) on November 20, 2019. Written consent was obtained from the patient's legal guardians.

Exclusion criteria are (1) patients with incomplete clinical data or radiographs; (2) open or pathological fracture; (3) presence of concomitant injuries of the elbow (fractures or dislocation); (4) duration of injury to surgery, less than 3 weeks or more than 12 weeks; (5) follow-up period of less than 24 months; (6) patients older than 14 years at the time of surgery.

$\mathrm{BP}$ is expensive, and not covered by basic medical insurance in our province. The pros and cons of two fixation materials were explained to the parents, and let them choose accordingly. The patients were divided into two groups KW $(n=17)$ and BP group $(n=26)$. Baseline information, including sex, age, operative side, duration from injury to surgery, and implant choice, was reviewed. Radiographs and medical records were collected from the Hospital Database. Fracture displacement was evaluated according to the Song classification [10]. The function of the elbow joint was evaluated according to the Mayo elbow performance score (MEPS) [11]. Complications, including infection, avascular necrosis (AVN), stiffness of elbow joint, and implant prominence and exposure, were carefully recorded.

\section{Biodegradable pins}

Biodegradable Pins are made of a blend of L-lactide, D, L-lactide and trimethylene carbonate (TMC), with a diameter of $2.0 \mathrm{~mm}$ and length of $5.0 \mathrm{~cm}$.

\section{Surgical technique}

Under general anesthesia, a $4-6 \mathrm{~cm}$ incision was made on the lateral aspect of the elbow, exposing the lateral and anterior capitulum. After removing the scar tissue from the fracture site, the fragment was reduced and fixated by $2-3$ wires (diameter, $1.6 \mathrm{~mm}$ or $2 \mathrm{~mm}$ ) under direct visualization of the articular surface. During the surgery, meticulous care was taken to preserve the soft tissue attachment of the lateral condylar fragment posteriorly. The KWs were routinely buried under the skin at our institute (Fig. 1).

In the BP group, the length of $\mathrm{KW}$ inside the bony surface was measured and replaced by the BP of the same size and length. Besides, a "figure of 8-band wiring" using a 1-0 absorbable suture was routinely performed to strengthen the stability (Fig. 2).

After the surgery, the arm was immobilized in the long-arm slab in a functional position for 3-5 weeks.

\section{Postoperative care and follow-up}

The slab was removed at the out-patient visit about 3-5 weeks after the surgery and was dependent on the callus formation on the radiograph. The active exercise was encouraged after the slab removal. In the patients of the KW group, the removal of implants was scheduled after full consolidation of the fracture on the radiograph.

\section{Statistical analysis}

SPSS statistical package program (SPSS 19.0 version; SPSS Inc., Chicago, Illinois, USA) was used for statistical analysis. The categorical data were analyzed using the Chi-square $\left(x^{2}\right)$ test, and the continuous data were analyzed using Student's t-test. Fisher exact test was used under those circumstances with fewer subjects in groups of interest. Data are presented as mean $\pm \mathrm{SD}$ (range), median (range) or $\mathrm{n}(\%) . P<0.05$ was considered significantly different.

\section{Results}

As shown in Table 1, 17 patients (male/female, 9/8) in KW and 26 patients (male/female,13/13) in the BP group were included in this study. The age showed no 

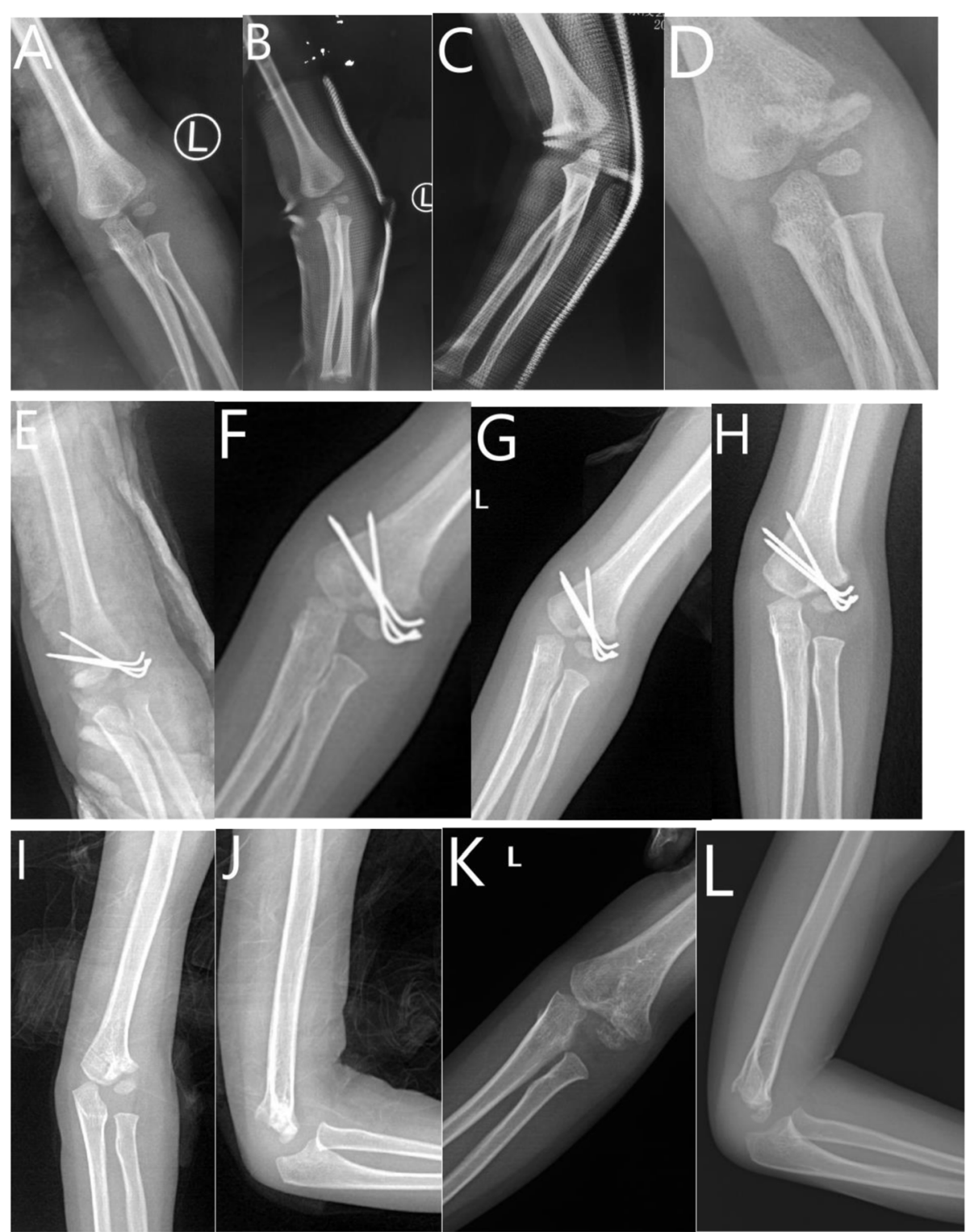

Fig. 1 Three year-old boy of left delayed LCF treated with ORIF. a AP view of elbow at injury. b AP view of elbow 2 weeks after injury. c Lateral view of elbow 2 weeks after injury. $\mathbf{d}$ AP view of elbow 5 weeks after injury. e AP view of elbow after surgery. $\mathbf{f}$ AP view of elbow at 5 th week follow-up. $\mathbf{g}$ AP view of elbow at 2nd month follow-up. $\mathbf{h}$ AP view of elbow at 4th month follow-up. $\mathbf{i}$ AP view of elbow at 9th month follow-up. j Lateral view of elbow at 9th month follow-up. $\mathbf{k}$ AP view of elbow at 25th month follow-up. I Lateral view of elbow at 25th month follow-up

statistically significant difference between the KW $(52.3 \pm 10.2$, month) and the BP $(56.1 \pm 10.7$, month), $(P=0.258)$. There was no statistically significant difference between the two groups concerning other parameters such as sex, fracture side, and Song classification. But the duration from injury to surgery is longer in the BP group ( $55.7 \pm 14.5$, day) than the KW group (45.1 \pm 15.5, day), $(P=0.034)$.

As shown in Table 2, there was no significant difference between KW and BP on preoperative MEPS $(P=$ 0.409). At the last follow-up, there existed no significant difference between the two groups concerning
Baumann's angle $(P=0.272)$ and carrying angle $(P=$ 0.911). The MEPS at the last follow-up was better in the KW group $(91.1 \pm 2.7)$ than the BP group $(89.2 \pm 3.0)$, $(P=0.048)$.

As shown in Table 3, there was no case of nonunion or malunion observed in both groups. The incidence of implant exposure was higher in $\mathrm{KW}(2 / 17,11.8 \%)$ than BP (0). The incidence of superficial infection is higher in KW $(3 / 17,17.6 \%)$ than BP (0), but there was no case of revision for infection. Besides, there was no case of unresolved stiffness, pain, and AVN in both groups. The incidence of fishtail deformity was $(8 / 17,47.1 \%)$ in $\mathrm{KW}$ and 

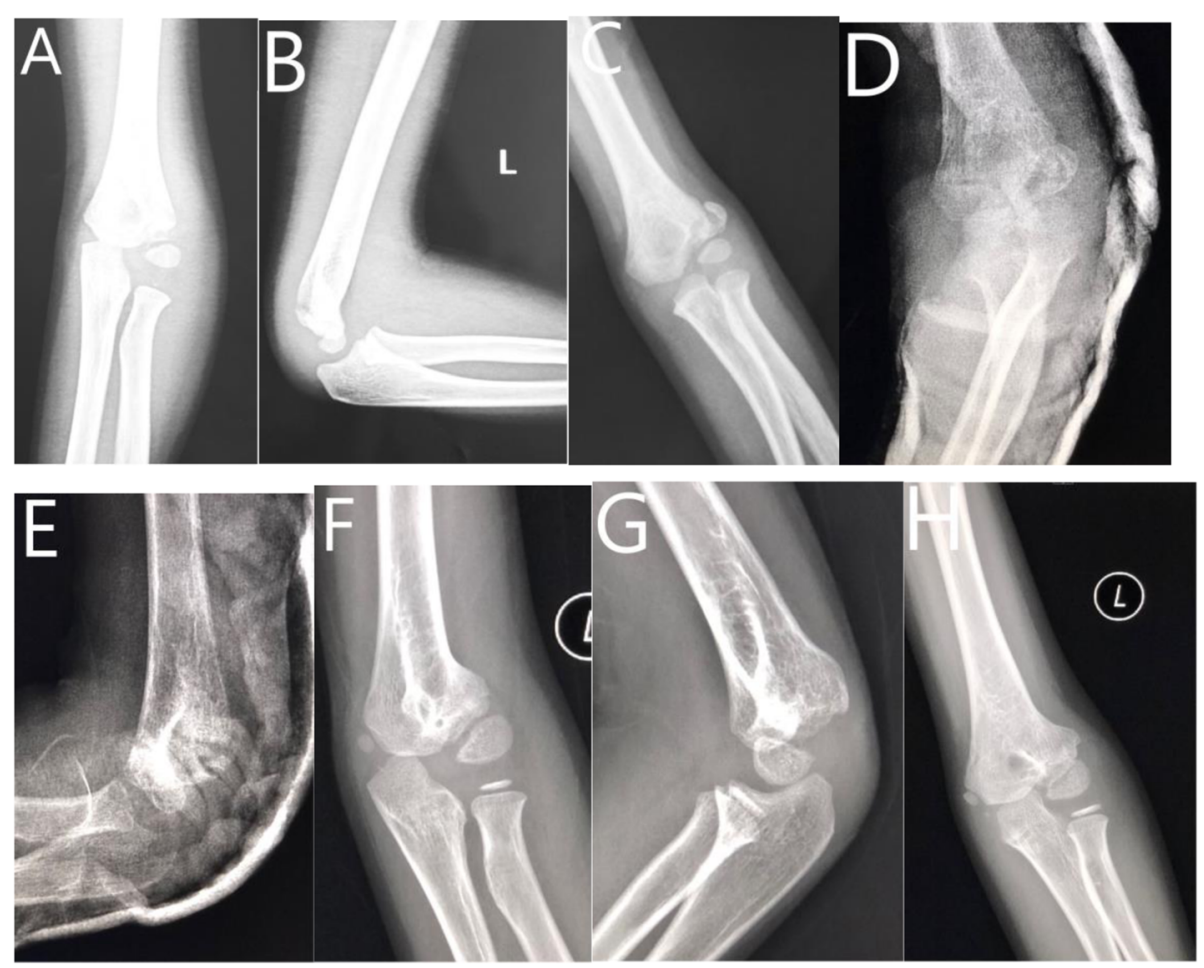

Fig. 2 Six-year-old boy of left delayed lateral condylar fracture treated with BP. a AP view of elbow joint at the time of injury. $\mathbf{b}$ Lateral view of elbow joint at the time of injury. c AP view of elbow joint at 6th week follow-up after initial injury. $\mathbf{d}$ AP view of elbow joint after surgery. $\mathbf{e}$ Lateral view of elbow joint after surgery. $\mathbf{f}$ AP view of elbow joint at 16th month follow-up after surgery. $\mathbf{g}$ Lateral view of elbow joint at 16 th month follow-up after surgery. $\mathbf{h}$ AP view of elbow joint at 25th month follow-up after surgery

(13/26, 50\%) in the BP group. The incidence of lateral prominence was $(5 / 17,29.4 \%)$ in KW and $(7 / 26,26.9 \%)$ in the BP group. Furthermore, the incidence of implant prominence was higher in KW $(12 / 17,70.6 \%)$ than $\mathrm{BP}$ (0) $(P<0.001)$.

\section{Discussion}

ORIF for LCF with an early-delayed presentation produced satisfactory clinical outcomes. BP requires no secondary surgery for hardware removal, with comparable clinical outcomes with KW.

Delayed LCFH in children is not common, and only a few case series have been reported $[4,5,12,13]$. Besides,

Table 1 Demographics of the patients

\begin{tabular}{llll}
\hline Parameters & KW $(\boldsymbol{n}=\mathbf{1 7})$ & $\mathbf{B P}(\boldsymbol{n}=\mathbf{2 6})$ & $\boldsymbol{P}$ value \\
\hline Age (months) & $52.3 \pm 10.2$ & $56.1 \pm 10.7$ & 0.258 \\
Sex (male/female) & $9 / 8$ & $13 / 13$ & 0.852 \\
Side (left/right) & $8 / 9$ & $13 / 13$ & 0.852 \\
From injury to surgery (d) & $45.1 \pm 15.5$ & $55.7 \pm 14.5$ & $0.034^{*}$ \\
Song Classification & & & \\
$\quad$ Type III & 11 & 18 & 0.142 \\
$\quad$ Type IV & 6 & 8 & \\
\hline${ }^{*}<0.05$ & & &
\end{tabular}

the optimal choice of treatment for this condition remains controversial $[2,3,8]$. The conservative method possibly results in poor clinical outcomes, including pain, instability of elbow joint, cubitus valgus deformity, and resultant ulnar nerve palsy $[3-5,12]$. However, surgical intervention carries a potential risk of AVN, infection, stiffness of the joint, and growth disturbance of distal humerus $[14,15]$. In patients with delayed presentation over 3 months, the morphology of the lateral condyle becomes unrecognizable and extensive dissection is usually required, which would compromise the vascular supply to lateral condyle fragment [16]. However, satisfactory outcomes have been reported in recent studies $[4,5,14]$, especially in patients with an early-delayed presentation [3]. Therefore, ORIF was adopted at our institute for delayed LCFH.

Table 2 Clinical outcome of the patients

\begin{tabular}{llll}
\hline Clinical outcomes & KW $(\boldsymbol{n}=\mathbf{1 7})$ & BP $(\boldsymbol{n}=\mathbf{2 6})$ & $\boldsymbol{P}$ value \\
\hline Baumann's angle & $19.2 \pm 4.7$ & $17.6 \pm 4.5$ & 0.272 \\
Carrying angle & $5.2 \pm 3.2$ & $5.3 \pm 2.8$ & 0.911 \\
Preoperative MEPS & $64.6 \pm 3.1$ & $65.4 \pm 2.6$ & 0.409 \\
MEPS at last follow-up & $91.1 \pm 2.7$ & $89.2 \pm 3.0$ & $0.048^{*}$ \\
\hline
\end{tabular}


Table 3 Complications of the patients

\begin{tabular}{llll}
\hline Complications & KW $(\boldsymbol{n}=\mathbf{1 7})$ & $\mathbf{B P}(\boldsymbol{n}=\mathbf{2 6})$ & $\boldsymbol{P}$ value \\
\hline Nonunion & 0 & 0 & 1 \\
Malunion & 0 & 0 & 1 \\
Exposure of implant & $2(11.8 \%)$ & 0 & 0.076 \\
Revision after infection & 0 & 0 & 1 \\
AVN & 0 & 0 & 1 \\
Unresolved stiffness & 0 & 0 & 1 \\
Fishtail deformity & $8(47.1 \%)$ & $13(50.0 \%)$ & 0.852 \\
Pain & 0 & 0 & 1 \\
Implant prominence & $12(70.6 \%)$ & 0 & $<0.001^{*}$ \\
Lateral prominence & $5(29.4 \%)$ & $7(26.9 \%)$ & 0.835 \\
Superficial infection & $3(17.6 \%)$ & 0 & $0.028^{*}$ \\
\hline${ }^{*}<0.05$ & & &
\end{tabular}

Cannulated screw has been proposed for fresh LCFH $[17,18]$, and it has also been used in delayed cases [4, 5, 12]. ORIF with a screw delivers more inter-fragmentary compression across the fracture line and provides more stability [10]. However, it might not be practical, especially in younger children in whom the fracture fragment is relatively small and mostly cartilaginous. Besides, the metallic screw necessitates a second surgery for hardware removal. At our institute, the cannulated screw is usually used in delayed LCFH over 3 months. Before the introduction of BP, KW was our preferred choice for LCFH with an early-delayed presentation. There was also a report on the use of a single bioabsorbable screw for displaced LCFH [19], but the lateral condylar fragment in the younger children is too small for a $3.5 \mathrm{~mm}$ screw; besides, one screw is not able to resist the rotational force. BP has been used at our institute for fresh LCFH since 2008, and the clinical outcome was satisfactory [20], consistent with the previous study [21]. The advantages of biodegradable material for fracture fixation is retaining the stability of metallic hardware without the need for implant removal operation [19-21]. As shown in the result, the clinical outcome in the KW group was satisfactory, consistent with the previous report [3]. Therefore, BP was used for LCFH with an early-delayed presentation thereafter. To our knowledge, it is the first report of BP in delayed LCFH in children.

For delayed LCFH over 3 months, a cannulated screw combined with KW is our preferred choice, due to the better compression effect of the screw and possible bone defect after extensive dissection. Moreover, bone grafting was not necessary for our patients due to limited bone defects after reduction, consistent with previous reports $[3,22]$.
The clinical outcomes in both groups were satisfactory with a low rate of complications and were comparable with the outcomes of ORIF for fresh LCFH [23]. However, the incidence of implant prominence was found higher in the KW group, since the end of the KW was bent to be buried under the skin while the pins in the $\mathrm{BP}$ group was cut along the bony surface. In younger patients, the prominence might hinder functional training. However, the clinical outcomes at the last follow-up showed no significant difference between the two groups. Although whether KW should be buried remains controversial $[24,25]$, but the healing time of delayed LCFH is estimated to be longer than fresh fracture. Therefore, KW was buried under the skin to lower the incidence of pin tract related complications at our institute.

There was no case of nonunion or malunion in both groups, possibly because of limited dissection and careful preservation of soft tissue attachment. The incidence of fishtail deformity in both groups was not significantly different, but much higher than ORIF for fresh LCFH [26], partly due to the stripping of fibrous tissues around the fragment. The incidence of lateral prominence and superficial infection in our study is comparable to ORIF for fresh LCFH $[2,23]$.

There were certain limitations to this study. The sample size was relatively small because this condition was not common. We undertook a retrospective investigation; therefore, our findings should be interpreted with caution. The allocation process of patients to either the KW group or BP group partly depended on the preference of the surgeon in charge, and this strategy may cause allocation bias. Besides, the biodegradable pins were more expensive (500-600 US dollars for each pin) than K-wires (5-10 US dollars), and it was not covered by the basic medical insurance in our province. Costeffective analysis remains to be investigated. In the future, prospective, well-designed randomized control trials will be required to validate the advantages of biodegradable material for the treatment of LCFH.

\section{Conclusion}

Open reduction and internal fixation for LCFH with an early-delayed presentation produced satisfactory outcomes. Biodegradable pin is a good alternative to Kirschner wire, with comparable clinical outcomes.

\footnotetext{
Abbreviations

LCFH: Lateral condylar fracture of the humerus; KW: Kirschner wire;

BP: Biodegradable pin; AVN: Avascular necrosis; ORIF: Open reduction and internal fixation
}

Acknowledgements

Not applicable. 


\section{Authors' contributions}

$\mathrm{PH}^{*}$ is in charge of the main idea and is the guarantor of integrity of the entire clinical study; $J \mathrm{~L}$ and $\mathrm{RHZ}$ are in charge of the study concepts, design, manuscript preparation and editing; PH and SR are in charge of the language polishing and the grammar revision; $\mathrm{YG}, \mathrm{RKL}$ and $\mathrm{XT}$ is in charge of the collection of the study data. All authors read and approved the final manuscript.

\section{Funding}

None.

\section{Availability of data and materials}

The data sets supporting the conclusion of this article are included within the article. Upon request, raw data can be provided by the corresponding author.

\section{Ethics approval and consent to participate}

This study was approved by the Ethics Committee of Tongji Medical College, Huazhong University of Science and Technology (IORG no: IORG0003571) on November 20, 2019. Written consents to participate in this study were obtained from the legal guardians of every patient.

\section{Consent for publication}

Written consents were obtained from the legal guardians of every patient in this study for publication of this paper.

\section{Competing interests}

The authors declare that they have no competing interests.

\section{Author details}

'Department of Orthopaedic Surgery, Union Hospital, Tongji Medical College, Huazhong University of Science and Technology, Wuhan 430022, China. 2Department of Orthopaedics and Trauma Surgery, National Trauma Center, National Academy of Medical Sciences, Mahankal, Kathmandu, Nepal. ${ }^{3}$ Department of Orthopaedic Surgery, Zhuhai Center for Maternal and Child Health Care, Zhuhai, China. ${ }^{4}$ First School of Clinical Medicine, Tongji Medical College, Huazhong University of Science and Technology, Wuhan, China.

Received: 13 May 2020 Accepted: 5 November 2020

Published online: 11 November 2020

\section{References}

1. Beaty $\mathrm{JH}$. Fractures of the lateral humeral condyle are the second most frequent elbow fracture in children. J Orthop Trauma. 2010;24:438.

2. Mounsey EJ, Howard A. Evidence-based treatments of paediatric elbow fractures. In: Alshryda S, Huntley JS, Banaszkiewicz PA, editors. Paediatric Orthopaedics. Cham: Springer International Publishing; 2017. p. 305-15.

3. Liu TJ, Wang EB, Dai Q, Zhang L, Li QW, Zhao Q. Open reduction and internal fixation for the treatment of fractures of the lateral humeral condyle with an early delayed presentation in children: a radiological and clinical prospective study. Bone Joint J. 2016;98-B(2):244-8.

4. Agarwal A, Qureshi NA, Gupta N, Verma I, Pandey DK. Management of neglected lateral condyle fractures of humerus in children: a retrospective study. Indian J Orthop. 2012;46:698-704.

5. Saraf SK, Khare GN. Late presentation of fractures of the lateral condyle of the humerus in children. Indian J Orthop. 2011;45:39-44.

6. Jakob R, Fowles JV, Rang M, Kassab MT. Observations concerning fractures of the lateral humeral condyle in children. J Bone Joint Surg (Br). 1975;57:430-6.

7. Flynn JC. Nonunion of slightly displaced fractures of the lateral humeral condyle in children: an update. J Pediatr Orthop. 1989;9:691-6.

8. Ganeshalingam R, Donnan A, Evans O, Hoq M, Camp M, Donnan L. Lateral condylar fractures of the humerus in children: does the type of fixation matter? Bone Joint J. 2018;100-B(3):387-95.

9. Schlitz RS, Schwertz JM, Eberhardt AW, Gilbert SR. Biomechanical analysis of screws versus K-wires for lateral humeral condyle fractures. J Pediatr Orthop. 2015;35:93-7.

10. Song KS, Kang CH, Min BW, et al. Closed reduction and internal fixation of displaced unstable lateral condylar fractures of the humerus in children. J Bone Joint Surg Am. 2008;90:2673-81.
11. Schneeberger AG, Kösters MC, Steens W. Comparison of the subjective elbow value and the Mayo elbow performance score. J Shoulder Elb Surg. 2014;23(3):308-12

12. Bae $\mathrm{KC}$, et al. Surgical treatment of late presented displaced lateral condylar fracture of the Humerus in children. J Korean Orthop Assoc. 2008;43(1):24-9.

13. Wattenbarger JM, Gerardi J, Johnston CE. Late open reduction internal fixation of lateral condyle fractures. J Pediatr Orthop. 2002;22(3):394-8.

14. Mulpruek $P$, Angsanuntsukh C, Woratanarat $P$, Sa-Ngasoongsong $P$, Tawonsawatruk T, Chanplakorn P. Shaft-condylar angle for surgical correction in neglected and displaced lateral humeral condyle fracture in children. Acta Orthop Belg. 2015;81(3):384-91.

15. Eamsobhana $P$, Kaewpornsawan K. Should we repair nonunion of the latera humeral condyle in children? Int Orthop. 2015;39:1579-85.

16. Dhillon KS, Sengupta S, Singh BJ. Delayed management of fracture of the lateral humeral condyle in children. Acta Orthop Scand. 1988:59(4):419-24.

17. Li WC, Xu RJ. Comparison of Kirschner wires and AO cannulated screw internal fixation for displaced lateral humeral condyle fracture in children. Int Orthop. 2012;36:1261-6.

18. Shirley E, Anderson M, Neal K, Mazur J. Screw fixation of lateral condyle fractures: results of treatment. J Pediatr Orthop. 2015:35:821-4.

19. Su Y, Chen K, Qin J. Retrospective study of open reduction and internal fixation of lateral humeral condyle fractures with absorbable screws and absorbable sutures in children. Medicine. 2019;98(44):e17850.

20. Li J, Rai S, Liu Y, Ze R, Tang X, Liu R, Hong P. Is biodegradable pin a good choice for lateral condylar fracture of humerus in children: a comparative study of biodegradable pin and Kirschner wire. Medicine (Baltimore). 2020; 99(33):e21696

21. Hope PG, Williamson DM, Coates CJ, Cole WG. Biodegradable pin fixation of elbow fractures in children. A randomised trial. J Bone Joint Surg (Br). 1991;73-B:965-8.

22. Chhetri RS, Dhakal I, Gnawali G. Operative management of late presented displaced lateral condyle fracture of humerus in children. JNMA J Nepal Med Assoc. 2018;56(209):527-30.

23. Pace $J$, Arkader A, Sousa T, Broom AM, Shabtai L. Incidence, risk factors, and definition for nonunion in pediatric lateral condyle fractures. J Pediatr Orthop. 2018;38(5):e257-61.

24. De Das S, Bae DS, Waters PM. Displaced humeral lateral condyle fractures in children: should we bury the pins? J Pediatr Orthop. 2012;32:573-8.

25. Raghavan R, Jones A, Dwyer AJ. Should Kirschner wires for fixation of lateral humeral condyle fractures in children be buried or left exposed? A systematic review. Orthop Traumatol Surg Res. 2019;105(4):739-45.

26. Tan SHS, Dartnell J, Lim AKS, Hui JH. Paediatric lateral condyle fractures: a systematic review. Arch Orthop Trauma Surg. 2018;138(6):809-17.

\section{Publisher's Note}

Springer Nature remains neutral with regard to jurisdictional claims in published maps and institutional affiliations.

Ready to submit your research? Choose BMC and benefit from:

- fast, convenient online submission

- thorough peer review by experienced researchers in your field

- rapid publication on acceptance

- support for research data, including large and complex data types

- gold Open Access which fosters wider collaboration and increased citations

- maximum visibility for your research: over $100 \mathrm{M}$ website views per year

At $\mathrm{BMC}$, research is always in progress.

Learn more biomedcentral.com/submissions 